discrete energy distribution, of which the hardest three components would have absorption coefficients of the order of $0.0018,0.0039$ and 0.0057 $\mathrm{gm} .^{-1} \mathrm{~cm} .^{2}$. The $B$ component would give secondary radiations of the same nature as the secondaries issuing from $A$, with an energy distribution as yet unknown, but corresponding to an absorption coefficient of the order of $0.0027 \mathrm{gm}^{-1} \mathrm{~cm} .^{2}$.

The $A$ and $B$ components may perhaps be identified with Regener's components $H_{1}$ and $H_{2}$; their respective magnetic hardness $X_{0}$, calculated by the method proposed by Heisenberg ${ }^{6}$, gives the right order of magnitude, if we assume that the primary rays are $\alpha$-particles. If we suppose that $X_{0} A$ is exactly equal to 0.30 , we find $X_{0} B=0.50$; this gives a good reproduction of Clay's curves ( $J$ vs. $\lambda)$ at sea-level. However, Regener's values for the respective intensity of those components at the earth's surface are not in good agreement with our hypothesis. But it must bo noted that the calculation of those intensities requires many assumptions about the secondary emission mechanism ; it might be, therefore, that a new discussion of deep water measurements, with different assumptions, would give values more in accordance with magnetic effects.
Our hypothesis is also in quantitative agreement with the east-west asymmetry observed by $\mathrm{H}$. Johnson and others. Quantitative divergences from those measurements may be attributed to the fact that we know little about the angular distribution of secondaries around the primary direction; and also to the fact that no account has been taken of the atmospheric electrical field effect. This effect is not negligible for the softer part of the radiation responsible for east-west asymmetry, as a calculation of a lower limit of the variation of the angle of incidence $\beta$ of rays gives : $\Delta \tan \beta= \pm 515 . E^{-1 / 2}$ (where $E$ is the energy of the ray, in electron-volts).

A more detailed account of the experiments described above will be published soon. The measurements were made possible by the help of the Belgian "Fonds National de la Recherche Scientifique", with the advice of Prof. A. Piccard and with the very efficient help of N. Van der Elst.

\footnotetext{
${ }^{1}$ Bauer, Terr. Mag., 28, 1; 1923.

${ }^{2}$ Lemaître and Vallarta, Phys. Rev. 43, 87; 1933. Lemaitre and Bouckart, Ann. Soc. Sci. Brux., 54, A, $162 ; 1934$.

${ }^{3}$ Clay, Physica, 1, 5, 376; 1933.

- Compton, Phys. Rev., 43, 387; 1933.

Lenz, Z. Phys., 83, 194; 1933. Gross, Z. Phys., 83, 214; 1933.

'Heisenberg, Ann. Phys., 13, 430; 1932.
}

\title{
National Water Policy in Great Britain
}

$\mathrm{T}$ HE recently issued report of the Joint Conference of the Institution of Water Engineers, the British Waterworks Association and the Water Companies Association on national water policy is a document of considerable interest, dealing, as it does, with a matter of vital public importance which has been debated for some time past in the Press, in Parliament and in various other quarters. It is to be regretted, however, that the Committee to which the question has been referred, appears to have been composed of representatives or consultants of water supply undertakings (mainly municipal) for domestic purposes, and, so far as can be gathered from a scrutiny of the names of the members, there was no direct representation of the commercial and industrial users of water, as also of other interests no less vitally concerned in the exploitation of the country's supplies. Land drainage and the prevention of floods, although necessarily bound up in any national water policy, evidently did not come within the purview of the Committee. Neither has any consideration been given to the aspects of the matter as affecting fisheries, navigation, canal sources of supply, and the like. The report is concerned solely with the allocation of water supplies to domestic uses.

The first matter dealt with is the proposed establishment of a 'water grid', put forward some time ago by Mr. Alan Chorlton, M.P., and advocated by him in a presidential address to the Institution of Mechanical Engineers in October 1933. This scheme, which is based on the analogy of the electricity grid, is condemned in the report in no uncertain terms. "We are definitely of opinion," states the Committee, "that as regards water supply, such a system is totally unjustifiable from every point of view, and especially in its economic aspect." The proposal is analysed in detail in a memorandum attached as an appendix to the report, summarising the objections under eight heads, which, for reasons of space, cannot be discussed here. Although, perhaps, controversial in some respects, they are weighty in substance and the cumulative effect is decidedly condemnatory. The Committee expresses itself as quite satisfied with the status quo. "In the unusual difficulties resulting from the recent exceptional drought, the water undertakers of this country have generally proved themselves well qualified to protect the true interests of their consumers and to meet their obligations to the public at large." Accordingly, the Committee is equally averse to the nationalisation of water supplies under a National Water Board. It considers the Ministry of Health to be the proper central water authority, and puts forward a proposal to meet the conditions at present prevailing by the "creation of a distinct, separate and specialised Water Department of the Ministry of Health", with various powers which are set out in detail.

It is perhaps not surprising that a Committee, constituted as stated above, should affirm its faith in the Ministry of Health as the sole suitable arbiter and dispenser of water throughout the country, but for the reasons already given, this can only be considered as a one-sided view. Other interests will scarcely be disposed to agree to such a monopoly. The British Association Research Committee on Inland WaterSurvey, whose investigations are referred to noncommittedly, has been urging the establishment of a national survey of water supplies on a purely scientific basis under the Department of Scientific and Industrial Research. The Government, while acceding to the overwhelming demand for a survey, has seen fit to disregard this recommendation and to place the survey in the hands of the Ministry of Health. It is difficult to appreciate the grounds upon which this step has been taken, since no analogous example from the practice of other countries have been cited in support of it. That the Ministry of Health, the proper functions of which are clearly indicated in its designation, should intervene in other spheres where its action and control might be misguided and detrimental, is a matter great ly to be deprecated. BRYsSon CunNINGHAM. 